\title{
Application of a Multiple-Trait Herd Cluster Model for Genetic Evaluation of Dairy Sires from Seventeen Countries
}

\author{
N. R. Zwald,* K. A. Weigel," W. F. Fikse,† and R. Rekaya* \\ *Department of Dairy Science \\ University of Wisconsin, \\ Madison 53706 \\ †Interbull Centre, \\ Department of Animal Breeding and Genetics, \\ Swedish University of Agricultural Sciences, \\ S-570 07 Uppsala, Sweden
}

\begin{abstract}
The multiple-trait across country evaluation method is currently used for international genetic evaluation of dairy sires. This method simultaneously combines national estimated breeding value (EBV) of sires in all countries and produces a separate breeding value to be used in each of the 24 countries that participate in the service. The major drawbacks to this method are the large number of genetic parameters that must be estimated and the large number of EBV produced for each sire. In the current method, each sire receives an EBV for each separate environment, and environments change at the country borders. It is unreasonable to assume that each country contains only one homogeneous environment and that every country has a distinctly different environment from all others. In the present study, an alternative method for international sire evaluation was utilized. Herds were grouped according to important management, climatic, and genetic factors rather than country borders. Data consisted of 16,403,413 first lactation cows in Australia, Austria, Belgium, Canada, Czech Republic, Estonia, Finland, Germany, Hungary, Ireland, Israel, Italy, The Netherlands, New Zealand, South Africa, Switzerland, and the United States. Herds were grouped according to 13 descriptive herd variables, including temperature, rainfall, peak yield, persistency, herd-size, age at calving, seasonality of calving, standard deviation of milk yield, culling percentage, fat-to-protein ratio, days to peak yield, percent of North American Holstein genes, and average PTA milk of sires. Variables were weighted by their relative importance in explaining genotype by environment interactions between herds. Herds were grouped into seven clusters; clusters ranged in size from
\end{abstract}

\footnotetext{
Received November 5, 2001.

Accepted March 2, 2002.

Corresponding author: N. Zwald; e-mail: nrzwald@ calshp.cals.wisc.edu.
}

4805 to 59,272 herds and $1,414,966$ to $3,966,431$ cows. The proposed model predicts EBV for dairy sires based on the production environment in which their progeny will perform, rather than the country where they will be located.

(Key words: international evaluation, genotype by environment interaction, herd clustering)

Abbreviation key: Interbull = International Bull Evaluation Service, MACE = multiple-trait across country evaluation, SSE $=$ Sum of squared errors.

\section{INTRODUCTION}

The number of dairy sires that are used for genetic improvement internationally is growing each year, and accuracy of genetic information for animals from all countries is increasingly important. The last major modification of international dairy sire evaluation methodology was in 1994 when the International Bull Evaluation Service (Interbull) implemented the multiple-trait across country evaluation (MACE) procedure (Schaeffer, 1994; Schaeffer et al., 1996). This allowed evaluations from progeny in multiple countries to be combined simultaneously, and international EBV could be calculated from relatives' information for bulls with progeny in only one country (Banos and Sigurdsson, 1995). However, this method treats progeny of a given sire differently based upon political or geographical boundaries regardless of the production environment in which these animals are actually performing. The MACE procedure considers lactation performance in small neighboring countries as different traits, and performance in large countries with varying management and climatic factors is considered a single trait (Cromie et al., 1998). Therefore, it cannot properly account for genotype $\times$ environment interaction between herds.

This is the latest in a series of papers from a larger study. Previous papers have examined the production systems in 17 leading dairy countries and identified management, climatic, and genetic factors that can ex- 
plain genotype by environment interactions between herds (Zwald et al., 2001). The present paper describes how such factors can be used to group herds into clusters or production environments for the purpose of international sire evaluation. In this approach, dairy sires no longer get an EBV for each individual country; they instead get an EBV for each unique production system (Lohuis and Dekkers, 1998; Weigel and Rekaya, 2000). Data from progeny and other relatives in different clusters can be used to predict the performance of each sire in each production environment that exists globally. This is a one-step method as opposed to the two-step approach that MACE currently uses. This method should increase the reliability and credibility of genetic information for dairy sires and should ultimately increase genetic progress in each production environment.

The objectives of this study were twofold: 1) to develop functions of 13 descriptive herd variables to define distinct production environments that account for the relative importance of each variable and the correlation between variables and 2) to apply this model to milk production data from 17 leading dairy countries.

\section{MATERIALS AND METHODS}

\section{Data}

The data consisted of $131,907,373$ test day records from 16,403,413 first lactation cows in 233,673 herds in Australia, Austria, Belgium, Canada, Czech Republic, Estonia, Finland, Germany, Hungary, Ireland, Israel, Italy, The Netherlands, New Zealand, South Africa, Switzerland, and the United States (Zwald et al., 2001). Cows were excluded if their first reported test date occurred $>90 \mathrm{~d}$ postpartum or if only one test date occurred during the lactation. Lactations were extended using the Wood's method (Wood, 1967). Herd means were calculated for each of the following variables: calendar day of calving (1-365), age at calving, days to peak yield, fat-to-protein ratio, herd size, percentage North American Holstein genes, peak yield, persistency, sire PTA milk (Interbull results on the US scale), annual rainfall, standard deviation of milk yield, and maximum monthly temperature (for description of variables, please see Zwald et al., 2001). Means for these variables were subsequently used to group herds into clusters or production systems for genetic evaluation purposes.

\section{Weighting Variables}

Because some variables are more important for explaining genotype by environment interaction than others, it was necessary to weight each of the 13 manage-
Table 1. Weights for each of the thirteen descriptive herd variables, based on the genetic correlations for milk yield between quintile groups for each variable.

\begin{tabular}{ll}
\hline Variable & Weight \\
\hline Peak yield & 0.2442 \\
Herd size & 0.2386 \\
Temperature & 0.1567 \\
Standard deviation of milk yield & 0.0863 \\
Percent North American Holstein & 0.0742 \\
Days to peak yield & 0.0668 \\
Rainfall & 0.0479 \\
Age at calving & 0.0195 \\
Percent of animals completing first lactation & 0.0169 \\
Persistency of yield & 0.0136 \\
PTAM of sires of cows currently in the herd & 0.0130 \\
Calving day & 0.0115 \\
Fat-to-protein ratio & 0.0109 \\
\hline
\end{tabular}

ment, climate, and genetic factors prior to the cluster analysis. Weights were developed from the genetic covariance matrices between herds at different levels for each of the 13 variables as shown by Zwald et al. (accepted). Covariance functions were applied to these matrices and the difference in the sum of squared errors (SSE) between the full-fit Legendre polynomial regression and its corresponding intercept term was calculated according to Pool and Meuwissen (2000). Each variable received an individual SSE, and weights were derived as a ratio of each variable's SSE:the total SSE (Kirkpatrick et al., 1990). For example, the estimated genetic variances in quintiles 1 through 5 for herd-size were $102,000,99,000,98,000,89,000$, and 62,000 . The first order (intercept term) of the genetic covariance function, which would be the estimate if all herds were treated as one environment, was estimated at 85,000. The SSE between each quintile variance estimate and 85,000 was calculated. This was also done for each covariance estimate, and the squared errors were then added together to get a total SSE for each variable. It was assumed that the variable with the largest SSE had the most variation between quintiles and, therefore, deserved the most weight in the subsequent analysis. The resulting weights are shown in Table 1.

\section{Factor Analysis}

To avoid double counting of correlated variables, a weighted factor analysis was used to develop unique contrasts of these variables. Seven factors had eigenvalues $>0.025$, and these factors explained nearly $94 \%$ of the total variation in the 13 original herd variables (Table 2). Scores for each of the seven factors were calculated for each herd, and these scores were used in the subsequent cluster analysis. Each of the seven factor scores for each herd was a composite of all 13 herd variables based on the eigenvectors in Table 3. For 
Table 2. Eigenvalues corresponding to each factor, and the proportion of the variation between the 13 variables that they comprise (individually and cumulatively).

\begin{tabular}{lcl}
\hline & Proportion of variation & \\
\hline Factor & Eigenvalue & Cumulative \\
\hline 1 & 0.382 & 0.382 \\
2 & 0.250 & 0.632 \\
3 & 0.122 & 0.754 \\
4 & 0.053 & 0.805 \\
5 & 0.049 & 0.858 \\
6 & 0.042 & 0.900 \\
7 & 0.038 & 0.939 \\
8 & 0.017 & 0.955 \\
9 & 0.016 & 0.971 \\
10 & 0.010 & 0.982 \\
11 & 0.007 & 0.989 \\
12 & 0.006 & 0.995 \\
13 & 0.005 & 1.000 \\
\hline
\end{tabular}

example, the first factor in Table 3 had the highest value on peak yield. This means that peak yield was the most important variable in determining factor 1 scores for each herd. Days to peak yield, fat-to-protein ratio, North American Holstein percentage, persistency, PTA milk, standard deviation of milk yield and temperature also have high values, and this indicates that these variables were also important in determining factor 1 scores for each herd. Herds with high values for most of these variables would get a high score for factor 1; likewise, herds with low values for these variables would receive a low score. Herd size was the most important variable in factor 2 and, therefore, large herds would generally get high scores for this factor. Interpretation of the remaining factors based on the eigenvectors in Table 3 is similar.

\section{Model}

A seven-trait BLUP sire model was used, and production in each cluster was considered a separate trait. A heterogeneous variance adjustment was applied to each herd using the method of Wiggans and VanRaden (1991). The model was as follows:

$$
\begin{aligned}
& \mathrm{y}_{\mathrm{ijk} l m n o p}=\text { hys }_{\mathrm{i}}+\mathrm{Herd}_{\mathrm{j}}+\text { Year }_{\mathrm{k}}+\text { Breed }_{\mathrm{l}}+\mathrm{Age}_{\mathrm{m}}+\mathrm{MF}_{\mathrm{n}} \\
& +\operatorname{sire}_{o}+e_{p}
\end{aligned}
$$

\begin{tabular}{|c|c|c|c|c|c|c|c|}
\hline \multirow[b]{2}{*}{ Variable } & \multicolumn{7}{|c|}{ Factor } \\
\hline & 1 & 2 & 3 & 4 & 5 & 6 & 7 \\
\hline Peak yield & 0.92 & -0.20 & -0.24 & 0.05 & -0.01 & -0.17 & -0.13 \\
\hline Herd size & 0.15 & 0.97 & -0.19 & 0.04 & -0.04 & 0.02 & -0.01 \\
\hline Temperature & 0.60 & 0.21 & 0.75 & 0.10 & -0.11 & -0.04 & 0.01 \\
\hline Standard deviation of milk yield & 0.76 & -0.02 & -0.16 & -0.27 & -0.01 & -0.01 & 0.56 \\
\hline North American Holstein percentage & 0.62 & -0.26 & -0.16 & 0.42 & 0.03 & 0.58 & 0.04 \\
\hline Days to peak yield & 0.53 & 0.19 & 0.23 & -0.53 & 0.47 & 0.26 & -0.22 \\
\hline Rainfall & -0.12 & 0.15 & 0.15 & 0.49 & 0.75 & -0.24 & 0.23 \\
\hline Age at calving & 0.12 & -0.19 & 0.15 & 0.02 & -0.45 & 0.25 & 0.10 \\
\hline Percent of animals completing first lactation & -0.21 & 0.14 & 0.02 & 0.07 & 0.14 & -0.12 & -0.11 \\
\hline Persistency of yield & 0.60 & -0.15 & 0.03 & -0.32 & 0.06 & 0.24 & -0.11 \\
\hline PTAM of sires of cows currently in the herd & 0.55 & -0.03 & -0.17 & 0.10 & 0.28 & 0.17 & -0.01 \\
\hline Calving day & -0.15 & 0.00 & -0.10 & 0.04 & 0.08 & -0.05 & 0.05 \\
\hline Fat-to-protein ratio & -0.58 & -0.11 & -0.24 & 0.02 & -0.11 & 0.05 & -0.05 \\
\hline
\end{tabular}

Bayesian implementation via Gibbs sampling was used to estimate the genetic covariance matrix between clusters so that heritability within each cluster and genetic correlations among clusters could be examined. Sire EBV were calculated in each cluster, and differences in sire rankings between clusters were examined. Due to the small number of animals in each herd-yearseason of some countries, fixed herd and year effects were used, but a random hys effect was also used to account for the nonrandom use of sires across herds and over time. A fixed breed effect with seven classes was used to account for varying levels of heterosis between breed combinations.

Table 3. Eigenvectors (weights) for each of the 13 descriptive herd variables corresponding to the seven factors that were retained. 


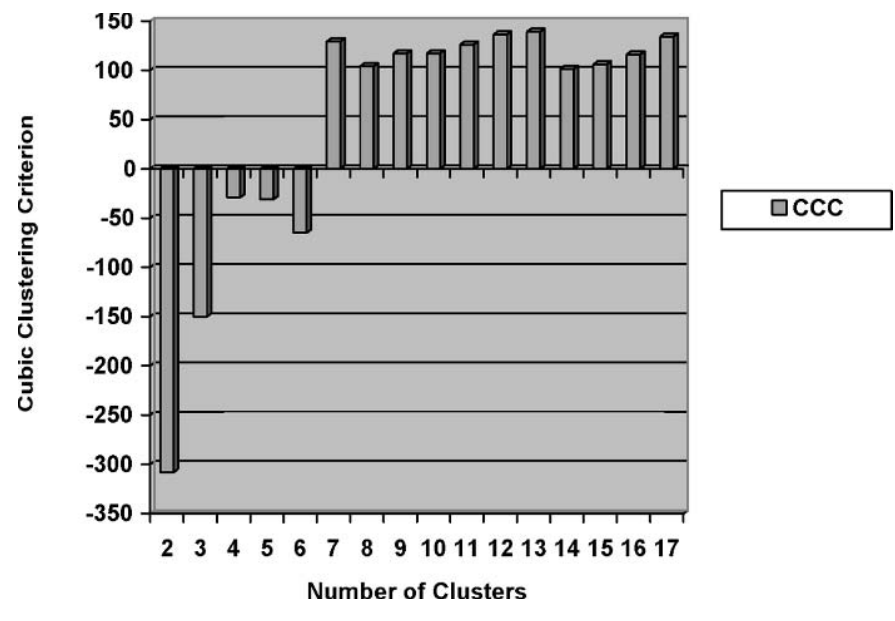

Figure 1. Cubic clustering criterion values for 2 to 17 clusters.

\section{Cluster Analysis}

The FASTCLUS procedure in SAS was used for herd clustering, which performs a disjoint cluster analysis based on Euclidean distances (SAS Technical Report, 1983). This iterative method guarantees that distances among observations in the same cluster will be less than the distances between observations in different clusters. For each herd, the 13 descriptive variables were combined into seven factors using the weights described above, and the cluster analysis was based on the seven factor scores for each herd. The optimal number of clusters was based on the cubic clustering criterion, which compares the observed R-squared to the expected $\mathrm{R}$-squared from a uniform distribution (SAS Technical Report, 1983). High values of the cubic clustering criterion indicate more clearly defined clusters.

\section{RESULTS AND DISCUSSION}

The relative importance of each variable in determining unique production environments is quantified in Table 1. Variables that were better predictors of genotype by environment interaction received the largest weights, and variables that were less informative received the smallest weights. Peak yield received the highest weight, because herds with different levels of peak yield had relatively low genetic correlations with each other. In contrast, fat-to-protein ratio received very little weight because herds with very different fatto-protein ratios had high genetic correlations with each other, and this indicated that fat-to-protein ratio did little to determine unique production environments. Table 3 shows the eigenvalues of the weighted correlation matrix for the 13 descriptive herd variables. These eigenvalues consider both the correlation between variables (Zwald et al, 2001) and the relative weights from Table 1. Although these weights are difficult to decipher, inspection of these values can indicate important variables in each factor. Factor 1 had a high positive weight on peak yield and standard deviation of milk yield and a large negative weight on fat:protein ratio. Therefore, herds with a low fat:protein ratio, high peak yield, and high standard deviation of milk yield had a high score for factor 1 . Herds that were very large with a low percentage of North American genes received a high score for factor 2 because of the large positive weight on herd size and the relatively large negative weight on North American Holstein percentage. Application of the cluster analysis to these factor scores led to seven herd clusters (Figure 1). Clusters ranged in size from 4805 to 59,272 herds and $1,414,966$ to $3,966,431$ cows.

Means of the 13 descriptive herd variables for each cluster are shown in Table 4, and the representation

Table 4. Means of descriptive herd variables corresponding to each cluster.

\begin{tabular}{|c|c|c|c|c|c|c|c|}
\hline Variable & \multicolumn{7}{|c|}{ Cluster } \\
\hline Age of calving & 27.5 & 28.5 & 28.5 & 28.8 & 24.4 & 27.4 & 27.2 \\
\hline Days to peak yield & 79.2 & 58.9 & 90.2 & 68.5 & 59.3 & 67.9 & 92.8 \\
\hline Fat-to-protein ratio & 1.22 & 1.28 & 1.26 & 1.23 & 1.31 & 1.27 & 1.15 \\
\hline Herd size & 86 & 9.5 & 11.4 & 11 & 25.3 & 9.5 & 19.8 \\
\hline Percent North American Holstein & 60.2 & 81.9 & 76.3 & 76.8 & 28.2 & 29.5 & 88.7 \\
\hline Persistency of yield & 0.755 & 0.753 & 0.805 & 0.776 & 0.604 & 0.745 & 0.842 \\
\hline PTAM of sires of cows currently in the herd & 173 & 196 & 166 & 229 & -238 & -231 & 700 \\
\hline Rainfall & 26.4 & 31.5 & 30.4 & 30.9 & 53.2 & 25.6 & 36.7 \\
\hline Standard deviation of milk yield & 1030 & 870 & 819 & 1259 & 579 & 825 & 1179 \\
\hline Temperature & 24.8 & 23 & 24.4 & 23.9 & 21.6 & 22.8 & 28.2 \\
\hline
\end{tabular}


Table 5. Percentage of cows from each country and region corresponding to each cluster.

\begin{tabular}{|c|c|c|c|c|c|c|c|c|}
\hline \multirow[b]{2}{*}{ Country/Region } & \multicolumn{7}{|c|}{$\%$} & \multirow[b]{2}{*}{ Total } \\
\hline & 1 & 2 & 3 & 4 & 5 & 6 & 7 & \\
\hline Australia total & 12 & 35 & 39 & 5 & 3 & 3 & 3 & 839,777 \\
\hline New South Wales & 1 & 3 & 38 & 7 & 31 & 0 & 20 & 89,166 \\
\hline Victoria & 3 & 52 & 37 & 5 & 0 & 2 & 1 & 495,053 \\
\hline Queensland & 0 & 6 & 86 & 6 & 0 & 1 & 2 & 65,860 \\
\hline South Australia & 58 & 9 & 25 & 3 & 0 & 4 & 1 & 129,824 \\
\hline Western Australia & 0 & 29 & 40 & 2 & 0 & 12 & 17 & 32,356 \\
\hline Tasmania & 27 & 27 & 34 & 0 & 0 & 11 & 0 & 27,518 \\
\hline Austria & 0 & 60 & 14 & 20 & 2 & 4 & 1 & 7,115 \\
\hline Belgium & 1 & 46 & 20 & 30 & 0 & 2 & 1 & 68,046 \\
\hline Canada total & 3 & 46 & 5 & 12 & 0 & 3 & 32 & $1,028,948$ \\
\hline PEI/Newfoundland & 0 & 49 & 5 & 21 & 0 & 0 & 24 & 11,565 \\
\hline Nova Scotia & 3 & 17 & 0 & 10 & 2 & 0 & 67 & 19,006 \\
\hline New Brunswick & 2 & 39 & 4 & 10 & 0 & 0 & 44 & 20,301 \\
\hline Quebec & 0 & 61 & 1 & 9 & 0 & 1 & 28 & 362,797 \\
\hline Ontario & 1 & 45 & 6 & 14 & 0 & 2 & 30 & 423,035 \\
\hline Manitoba & 3 & 36 & 16 & 17 & 0 & 7 & 21 & 27,225 \\
\hline Saskatchewan & 3 & 34 & 19 & 15 & 0 & 15 & 14 & 19,769 \\
\hline Alberta & 16 & 24 & 10 & 11 & 0 & 17 & 22 & 65,655 \\
\hline British Colombia & 8 & 11 & 2 & 9 & 0 & 1 & 69 & 79,595 \\
\hline Switzerland & 0 & 84 & 5 & 8 & 0 & 2 & 1 & 44,975 \\
\hline Czech Republic & 49 & 17 & 20 & 2 & 0 & 11 & 0 & 153,177 \\
\hline Germany total & 21 & 42 & 6 & 19 & 0 & 13 & 0 & $2,966,691$ \\
\hline North West Germany & 1 & 64 & 6 & 20 & 0 & 8 & 0 & $1,549,905$ \\
\hline North East Germany & 61 & 2 & 4 & 13 & 0 & 21 & 0 & 407,331 \\
\hline South East Germany & 61 & 3 & 3 & 15 & 0 & 17 & 0 & 569,856 \\
\hline South West Germany & 0 & 51 & 8 & 22 & 0 & 18 & 0 & 439,599 \\
\hline Estonia & 30 & 15 & 44 & 3 & 0 & 8 & 0 & 13,207 \\
\hline Finland & 0 & 0 & 1 & 3 & 0 & 97 & 0 & 111,789 \\
\hline Hungary & 63 & 1 & 29 & 5 & 0 & 1 & 1 & 265,820 \\
\hline Ireland & 3 & 25 & 21 & 3 & 0 & 47 & 1 & 124,731 \\
\hline Israel & 69 & 0 & 0 & 0 & 0 & 31 & 0 & 208,171 \\
\hline Italy total & 21 & 12 & 6 & 27 & 0 & 3 & 30 & $1,415,432$ \\
\hline Northern Italy & 20 & 7 & 5 & 24 & 0 & 2 & 42 & 943,123 \\
\hline Central-Northern Italy & 21 & 29 & 5 & 34 & 0 & 6 & 4 & 294,759 \\
\hline Central-Southern Italy & 17 & 18 & 15 & 34 & 0 & 5 & 11 & 67,950 \\
\hline Southern Italy & 30 & 8 & 14 & 27 & 0 & 11 & 11 & 109,600 \\
\hline The Netherlands & 1 & 78 & 7 & 11 & 0 & 1 & 2 & $1,476,972$ \\
\hline New Zealand total & 8 & 1 & 3 & 0 & 75 & 12 & 0 & $1,481,763$ \\
\hline Northern North Island NZ & 3 & 0 & 2 & 0 & 95 & 0 & 0 & 151,451 \\
\hline Central North Island NZ & 2 & 0 & 0 & 0 & 98 & 0 & 0 & 714,722 \\
\hline Southern North Island NZ & 7 & 0 & 0 & 0 & 92 & 0 & 0 & 124,161 \\
\hline Northern South Island NZ & 10 & 3 & 8 & 1 & 0 & 78 & 0 & 194,750 \\
\hline Central South Island NZ & 16 & 7 & 12 & 1 & 40 & 24 & 0 & 119,646 \\
\hline Southern South Island NZ & 32 & 4 & 3 & 1 & 60 & 0 & 0 & 177,033 \\
\hline United States total & 15 & 4 & 4 & 3 & 0 & 1 & 72 & $3,133,927$ \\
\hline Northeastern States & 8 & 2 & 3 & 3 & 0 & 0 & 83 & 897,870 \\
\hline Central States & 8 & 1 & 5 & 3 & 0 & 1 & 82 & 284,089 \\
\hline North Central States & 5 & 9 & 4 & 4 & 0 & 2 & 75 & $1,202,613$ \\
\hline Northwestern States & 25 & 1 & 9 & 2 & 0 & 1 & 61 & 183,486 \\
\hline South Central States & 15 & 0 & 10 & 1 & 1 & 1 & 72 & 79,286 \\
\hline Southeastern States & 13 & 0 & 3 & 3 & 5 & 0 & 76 & 170,369 \\
\hline Southwestern States & 72 & 0 & 4 & 1 & 0 & 2 & 21 & 316,214 \\
\hline South Africa & 31 & 4 & 33 & 18 & 0 & 3 & 11 & 117,615 \\
\hline Total & 15 & 27 & 8 & 11 & 9 & 7 & 23 & $13,458,156$ \\
\hline
\end{tabular}

of herds from each country or region in each cluster is shown in Table 5. Cluster 1 was comprised primarily of large herds in Eastern Germany, the Czech Republic, Italy, and the United States. These herds were characterized by extended days to peak yield, very large herd size, and relatively low annual rainfall. Cluster 2 was the largest cluster, and it consisted of smaller herds that used a large proportion of North American Holstein genetics and had moderate peak yield. This cluster included the majority of cows in the Netherlands as well as western Germany. Canada and Australia also had a large number of herds in this production environment. Cluster 3 was made up of small herds with low peak yield, extended days to peak yield, and high persis- 
Table 6. Heritability and genetic correlations between the seven environments (clusters).

\begin{tabular}{llllllll}
\hline \multicolumn{7}{c}{ Cluster } \\
\hline Cluster & 1 & 2 & 3 & 4 & 5 & 6 & 7 \\
\hline 1 & 0.33 & 0.92 & 0.91 & 0.94 & 0.68 & 0.95 & 0.91 \\
2 & & 0.39 & 0.96 & 0.97 & 0.64 & 0.91 & 0.95 \\
3 & & & 0.35 & 0.95 & 0.68 & 0.91 & 0.92 \\
4 & & & & 0.39 & 0.61 & 0.92 & 0.94 \\
5 & & & & & 0.24 & 0.75 & 0.59 \\
6 & & & & & & 0.42 & 0.85 \\
7 & & & & & & & 0.28 \\
\hline
\end{tabular}

tency. Australia, Germany, and the Czech Republic all had strong representation in this cluster. Cluster 4 largely consisted of herds from western Germany and Italy. These herds typically had an older age at first calving and a high standard deviation of milk yield. New Zealand herds made up over $97 \%$ of the cows in cluster 5 . This cluster was comprised of low peak yield, low persistency, low percentage of North American genes, and a high fat-to-protein ratio. Cluster 6 contained mainly small herds from northern Europe as well as a few herds from New Zealand. Cluster 7 consisted primarily of moderately-sized herds in the United States and Canada with very high peak yield, extended days to peak yield, and a high genetic level.

Heritability within clusters and genetic correlations between clusters are shown in Table 6 . Heritability ranged from 0.24 to 0.42 , and genetic correlations ranged from 0.59 , between low input grazing herds of New Zealand (cluster 5) and the intensely managed herds with high peak yields located primarily in the United States and Canada (cluster 7), to 0.97, between clusters 2 and 4 . The relatively low genetic correlation between the grazing herds of New Zealand (cluster 5) and the other clusters would suggest that the production environment that is present in these herds is significantly different from other environments around the world. Other genetic correlations between clusters have similar values to those between countries that are currently used by Interbull in the MACE procedure (Schaeffer, 1996). The high heritability estimates found for clusters 2, 4, and 6 can be explained in part by recognizing that those clusters generally had smaller herd sizes and, therefore, the heritability estimates may have been biased upward because of the herd variance adjustment used.

Further work is being done at the Interbull center to test and compare the results of MACE and the borderless evaluation methods proposed in this research.

\section{CONCLUSIONS}

An alternative method of evaluating dairy sires based on production environments was proposed and applied to data from 17 leading dairy countries. Intuitively, this model makes sense because animals in similar environments are grouped accordingly, regardless of country borders. Thus, genotype by environment interaction should be properly taken into account. Each of the 13 descriptive herd variables was assigned a weight based on genetic correlations between lactation performance in herds at different levels. Herd size, peak yield, and temperature were found to be the best predictors of genotype by environment interaction between herds. Many of the descriptive variables were highly correlated, and to avoid double counting certain variables, a factor analysis was used to create seven uncorrelated factors. Subsequently, seven clusters were formed using the management, genetic, and climatic information for each herd, and each of these clusters was considered as a separate trait for genetic evaluation purposes. Improvements could be made to this analysis by having specific temperature and rainfall estimates for each herd, as opposed to regional estimates. Traits other than milk production as well as the inclusion of multiple lactation records could also be evaluated to further distinguish between environments in the global dairy population.

Currently there are 27 separate countries (environments) in the routine Interbull sire evaluation system. Therefore, each dairy sire receives 27 different EBV. It does not seem logical to assume that each country is a single environment that is independent from similar environments in other countries. By using the proposed model, the number of unique production environments and, therefore, the number of EBV for each bull would be reduced to seven. Each sire would receive a separate evaluation in each of the seven unique production environments based on data from progeny and relatives in that cluster. Evaluations would also consider progeny performance in other clusters, but that information would be discounted based on the genetic correlations between the clusters.

The approach to international sire evaluation presented herein would be an improvement over the current system of evaluating sires, because it would properly account for management, climatic, or genetic differences between herds in large countries (e.g., tie-stall herds in Vermont versus large dairies in Arizona) by placing those herds in separate clusters, and it would also allow similarly managed herds in different countries to be treated as the same environment for genetic evaluation purposes (e.g., grazing herds in Ireland and Australia). Therefore, this system will lead to higher reliability and credibility of international sire EBV. Implementation of this model would mean that an individual sire would have seven international EBV, and different sire EBV would be appropriate for different herds 
within a country. However, national sire evaluations could still incorporate the use of more complex models with specific environmental factors to each country. National evaluations would also be needed for calculation of female evaluations, national indexes, and other health traits that are recorded in each individual country.

\section{REFERENCES}

Banos, G., and A. Sigurdsson. 1996. Contemporary methods for the use of international data in national genetic evaluations. J. Dairy Sci. 79:1117-1125.

Cromie, A. R., D. L. Kelleher, F. J. Gordon, and M. Rath. 1998. Genotype by environment interaction for milk production traits in Holstein-Friesian dairy cattle in Ireland. Proc. 1998 Interbull Mtg., Rotorua, New Zealand XVII:100-104.

HTTP://www.worldclimate.com. Accessed June 10, 2000.

Kirkpatrick, M., D. Lofsvold, and M. Bulmer. 1990. Analysis of the inheritance, selection, and evolution of growth trajectories. Genetics 124:979-993.

Lohuis, M. M., and J.C.M. Dekkers. 1998. Merits of borderless evaluations. Proc. 6th World Congr. Genet. Appl. Livest. Prod., Armidale, Australia XXVI:169-172.
Pool, M. H., and T.H.E. Meuwissen. 2000. Reduction of the number of parameters needed for a polynomial random regression test day model. Livest. Prod. Sci. 64:133-145.

Schaeffer, L. R. 1994. Multiple-country comparison of dairy sires. J. Dairy Sci. 77:2671-2678.

Schaeffer, L. R., R. Reents, and J. Jamrozik. 1996. Application of contemporary methods for the use of international data in national genetic evaluations. J. Dairy Sci. 79:1108-1116.

SAS Institute Inc., SAS Technical Report A-108, Cubic Clustering Criterion. 1983. SAS Institute, Inc., Cary, NC.

SAS OnlineDoc, V8. http://shelf.doit.wisc.edu/SasOnlineDocs/stat/ chap26. Accessed April-August 2001.

Wood, P.D.P. 1967. Algebraic model of the lactation curve in cattle. Nature 216:164-169.

Weigel, K. A., and R. Rekaya. 2000. A multiple-trait herd cluster model for international dairy sire evaluation. J. Dairy Sci. 83:815-821.

Wiggans, G. R., and P. M. VanRaden. 1991. Method and effect of adjustment for heterogeneous variance. J. Dairy Sci. 74:43504357.

Zwald, N. R., K. A. Weigel, W. F. Fikse, and R. Rekaya. 2001. Characterization of dairy production systems in countries that participate in the international bull evaluation service. J. Dairy Sci. 84:2530-2534.

Zwald, N. R., K. A. Weigel, W. F. Fikse, and R. Rekaya. Identification of Factors that cause Genotype by Environment Interaction in Countries that Participate in the International Bull Evaluation Service. J. Dairy Sci. (accepted). 